\title{
The naming of meals
}

\section{FÉLIX RODRÍGUEZ \\ GONZÁLEZ}

\author{
A survey of the words the British use for \\ everyday meals and a comparison with the \\ usages of French and Spanish
}

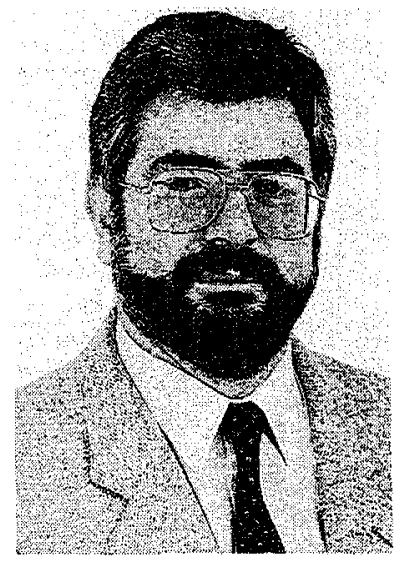

BECAUSE of social inequality and different cultural habits and life-styles, the names and times for meals can vary in many European languages and cultures. In a simplified way, however, we can distinguish three main meals, in a tripartite scheme that has existed since Roman times.

Of these meals, the last two have different names which are usually the object of sociolinguistic variation. This is particularly noticeable in international languages like English, French and Spanish, where along with their differences one can notice a certain parallelism in present and past usage, which immediately leads us to think of similar cultural referents. In this article I will focus primarily on English while also commenting, for purposes of comparison, on French and Spanish.

\section{The first meal: breakfast}

If there is some consensus today between speakers of English on both sides of the Atlantic, it is in naming the first meal of the day, breakfast (lit. 'breaking the fast' from the previous night), with an etymological basis similar to Fr. déjeuner and Sp. desayuno. The term is first attested in the second half of the 15th century (for example, brekfast/breffast in 1463). Its forerunner seems to have been Old English morgenmete 'morning food (meal)'.
The ingredients and size of the meal of course vary according to individual taste, among other factors, but in general we can distinguish two types in British usage: the continental breakfast, which consists of tea or coffee and toast, and the great (or full) British breakfast, which consists of tea or coffee, cereals and fried eggs with bacon (to which sometimes mushrooms, sausages, fried tomato, etc. are added).

In present-day standard terminology there is a term for breakfast taken at a later time and used as a substitute for the second meal, lunch. The blend brunch seems to have been

FÉLIX RODRIGUEZ is Associate Professor of English at the University of Alicante in Spain. He holds a doctorate in Romance Linguistics from the University of Alberta (Canada) and of English Philology from the University of Salamanca (Spain). He has published numerous articles on lexicology and sociolinguistics, which he teaches at the University of Alicante. His publications include books on slang" ('Comunicación y lenguaje juvenil', Madrid, 1989), political language ('Prensa y lenguaje politico', Madrid, 199I) and language contact ('Spanish loanwords in the English language', forthcoming). At present he is working on a dictionary of anglicisms in contemporary Spanish. The survey on which this paper is based was carried out thanks to a grant from the Conselleria de Cultura, Educaciò i Ciencia de la Generalitat Valenciana (Spain). 
coined by the British author Guy Beringer in 1896, and has kept part of its original artificial, humorous and affected connotation. However, in America it is widely used, to such an extent that it is often described as an Americanism. Generally, it refers to the first meal of a Sunday morning, often after having been at a party the previous night. In America the hotels announce 'Sunday brunches' served after 11 o'clock.

\section{The second (midday meal): lunch/ dinner}

The second standard meal, taken at midday, has two names in English, lunch and dinner, which show some denotative and connotative differences.

In the Middle Ages, dinner was the chief meal, taken originally between 9 in the morning and midday, which is a good reminder of its etymological meaning (from OFr. di(s)ner and ultimately from Lat. disjejunare, it meant likewise 'break one's fast'). One can understand the original aura of the term in the light of the prestige associated since Norman times with French cookery, as is reflected in present-day English culinary terminology (beef, mutton, dessert, etc.).

Lunch as a term designating a meal is considered to be a shortened form of luncheon and its first appearance is documented in 1829. Luncheon originally meant a thick piece or hunk, and later a light meal taken between two of the ordinary meal-times, especially between breakfast and midday dinner, thus with a meaning similar to the present-day British term elevenses. Luncheon, like lunch, was also used in a wider sense, as a meal taken at any time of the day, but in modern times the word has given way to snack. In its original sense, luncheon is, according to the $O E D$, probably an extension of lunch 'slice', perhaps derived from Spanish lonja (although to me its spelling variant loncha sounds more plausible) which has precisely that meaning.

As a name for a midday meal, lunch is used when the meal is customary and uneventful ('Pick me up for lunch'), and luncheon if it is a formal occasion. In the program of activities of the British royal family published daily in The Times, luncheon is the form always employed. Lunch can also serve as a verb ('Lunch with me') whereas luncheon is a noun only.
As to their social connotations, dinner is a term frequently used in Britain for the main midday meal among the lower classes and children, whereas lunch is especially used among the urban middle classes who postpone the chief meal until the evening.

The English writer George Orwell was aware of these class connotations when he wrote in his novel A Clergyman's Daughter: 'Luncheon, Dorothy, luncheon, said the Rector with a touch of irritation. I do wish you would drop that abominable lower-class habit of calling the midday meal dinner!'

\section{The third (and fourth) meal: dinner/ tea/supper}

The picture offered by the names of the third - and for most people, the last - meal is more complex still because of the number of meals as well as the polysemic value of one of its most important terms, dinner, used to designate the second as well as the third meal. In addition to dinner, in British English two other terms are also used: supper and tea.

Supper (super in Middle English) etymologically comes from Old French soper which was originally applied to the last meal of the day. Soper in its turn derived from Germanic suppa (cognate with soup), a word which was borrowed from the Franks, who used it to designate the piece of bread on which they poured the broth. Following this old use, supper now is applied to the meal taken at the close of the day when the main meal, the dinner, is taken at midday. It is generally less substantial and formal, hence expressions such as 'have cold meat for supper', 'have a late supper', 'eat very little supper'.

In line with this meaning, it is sometimes used to apply to a late meal following an early evening dinner, for example when coming home after the cinema or the theatre and before going to bed. In this sense it is a less formal meal than late dinner.

Nowadays, taken at an earlier time, supper can designate a meal made the occasion of a social or festive gathering, especially if it is held for raising funds for charitable or other purposes (e.g., church supper). A still more distinctive use of supper is the religious, for it is the term used to refer to the Eucharist or Holy Communion, as in the expressions The Lord's Supper, the Dominical Supper, the Last Supper, or simply, the Supper. 
Tea (or high tea) is the main meal if taken in the early evening (between 5 and 6 approximately), that is, between the midday lunch (or dinner) and a late supper. This meaning of tea is used in Britain especially by the working class, and in the north of England and in Scotland generally (e.g. 'I always come back to find the tea ready', 'at tea we all sat round the table and talked about the day's events').

The name tea also refers to a light meal taken in the afternoon between 4 and 5 , usually consisting of sandwiches, scones and cakes taken with tea. It is also more formally known or announced as aftermoon tea. This meaning of tea is used in Britain mainly by middle class people (e.g. 'Mr. Evans is coming to tea').

The widespread use of the term clearly shows how rooted the drink is in the food habits of the peoples of the British Isles. It is worth mentioning, however, that the term tea has a Chinese origin and is said to have been introduced to England around 1655, perhaps by the Dutch or the Portuguese.

A century later (c.1738), and as a result of further semantic change, the word came to designate a meal or social entertainment at which tea was served and later a meal in which tea need not be taken.

The adjective 'high', applied to food and drink to refer to their rich quality, was used with $t e a$, at least from the first half of the 19th century (e.g., 1831, as recorded by The Century Dictionary, 1889). High tea originally referred to a tea at which hot meat was served, in distinction from an 'ordinary' tea with bread, butter, cake, etc. Nevertheless, such a meal was usually less substantial and elaborate than dinner, hence less ceremonious. This fact, together with the popularity that tea as a beverage had gained among the lower class (after 1715, according to $\mathrm{Dr}$. Johnson), would partly account for the lower class connotation of the word, as in the following quote from the 19th century, recorded by J.A. Murray (1901): 'For people who are not in the habit of giving dinner parties . . . high tea is a capital institution.'

\section{Other terms}

Apart from the names of the three main meals, there are others which are occasional variants or correspond to intermediate or irregular meals. Earlier I referred to British elevenses and American brunch. The former, more frequently known today as coffee break, is taken between 10 and 11 and usually consists of coffee and biscuits.

For the light midday meal (lunch) there are other names. One of them, tiffin (or tiffing), etymologically a 'little drink', is primarily Anglo-Indian and is widely used in India instead of lunch. Other terms used in very restricted contexts [and recorded by Newmark], are dindins (a reduplication of the first syllable of dinner), which means a heavier meal for young children among the upper middle classes, and snap ('bite'), a packed lunch among the working class in northern England. Variations include fork lunch (a cold buffet eaten standing), ploughman's lunch (a simple pub lunch of bread, pickles, cheese and beer), and a wedding breakfast (a ceremonial morning meal after a wedding).

Other irregular meals are harvest supper (a meal in church hall, after harvest time), Christmas dinner (taken from 1 to 3 and consisting traditionally of turkey plus Christmas pudding), and tea break, the name the British give to the tea and biscuits taken in mid-morning or mid-afternoon (and, some would say, at every other opportunity available to the British working man).

Finally come the names for a light meal in a relatively non-specific sense: the formal collation, the informal bite, the originally Yiddish nosh (from the verb naschen 'to nibble or eat on the sly') and the currently frequently used snack, whose meaning of a mere bite or morsel, light meal, is first recorded in 1757 . Similar terms which have become obsolete or are dialectal include nacket, doggy, damper, biting-on, piece.

\section{Main meals: variation in use}

As noted earlier, variation in the use of names of meals occurs especially with the two most substantial, midday lunch/dinner and evening dinner/tea/supper. At first sight, the use of such terms should be easy to differentiate, given their different denotative meanings in terms of time and size, but difficulty arises when some crisscrossing or overlapping (social) factors are considered.

Generally speaking we can say that those who take a light lunch at midday do so because their main meal will be in the evening, and they will call it dinner. If they have 
their main cooked meal at midday, they will have a light supper (or tea) in the evening. But . at a social level we have a double schema: for many people, particularly working class (and above all manual workers), the main midday meal is dinner. The middle classes on the other hand prefer the term lunch for midday and dinner for the evening.

This pattern lunch and dinner is the most common today, especially in America, and it emerged in the first half of this century. According to Albert Marckwardt (American Language, 1958), in the early 20's and 1930's it was considered proper, particularly by women, to refer to the evening meal as dinner, and supper was old-fashioned. Luncheon/ lunch, for the same speakers, in turn replaced dinner as the designation of the midday meal.

This shift of terms is also interesting from a sociological point of view. According to Marckwardt, such a shift was a delayed reflection of the changed eating habits of many American families as a result of increased urbanization and industrialization. For farming and small-town families at the beginning of the century, the heaviest meal of the day was served at noon, and the evening meal was lighter. Thus for that time, dinner and supper could be considered appropriate terms, but soon afterwards they started to be replaced by lunch and dinner.

This terminological turnover can be explained by some of the social changes which began to occur in North America in the 20's: the disappearance of live-in servants in middle class households and new opportunities for women to work outside the home which brought about the use of new technical aids to housework. These changes no doubt contributed to the upset of the established manner of eating (The Rituals of Dinner, as Margaret Visser explains in a recent book by this title, Viking, 1992). And the process has been reinforced considerably in our age with our tendency toward casual informality in our meals, due to time constraints, which has a clear manifestation in our liking for fast food in McDonalds and lighter meals at noon (frequently consumed away from home, in the place of work or in public places like cafeterias and wine bars). Under these conditions one can understand why the heavier meal of the day (dinner), previously served at home, was shifted to the evening, with a resultant change of meaning and a gradual displacement of supper.

In Britain, the decline in the use of supper started to occur still earlier, in the 19th century, as is reflected in the comments of some mid-19th century British travelers. On the other hand, the changes which occurred there are similar to those produced in France; in fact they were produced by imitation of them, according to Mencken. But despite the establishment of dinner as the standard form for the evening meal in Britain, tea and supper also co-occur with a certain frequency, in marked contrast to the United States where $t e a$ is no longer used.

A good barometer for measuring the British and American differences found today is the terminology of the hotel trade, which is usually determined by two forces which do not coincide: the need to be precise and the frequency of the term. In the U.S., the examination of a number of meal adverts has led me to confirm the generalization of lunch and dinner, which indicates that dinner is not felt to be ambiguous. In Britain, however, the polysemy of this term explains its not infrequent replacement by other variants. I recall a sign with the times of the meals lunch and dinner exhibited on the outside door of the University of East Anglia main cafeteria, in marked contrast to another on the wall inside showing the menus for lunch and supper.

Despite the equivocal character shown by dinner in British English, the term is the most frequent in everyday speech, which results in a complex variation of the names of the meals. [The situation is further complicated by the general meaning that dinner has in English as it is often used as a generic name for a meal.]

The variation in the meal terms described has been registered in lexicographic works with unequal attention. Most dictionaries account for the denotative and contextual (stylistic) but rarely for the geographic or social differences. On this point it is worth mentioning the information gathered in Tom McArthur's Longman Lexicon of Contemporary English (1981), in a diagram for the names of meals, in which brief remarks about social and regional distribution as well as time of day, and other denotative features are included (see Panel 1).

Another interesting diagram is contained in Peter Newmark's A Textbook of Translation (Prentice Hall, 1988). No doubt this complex 


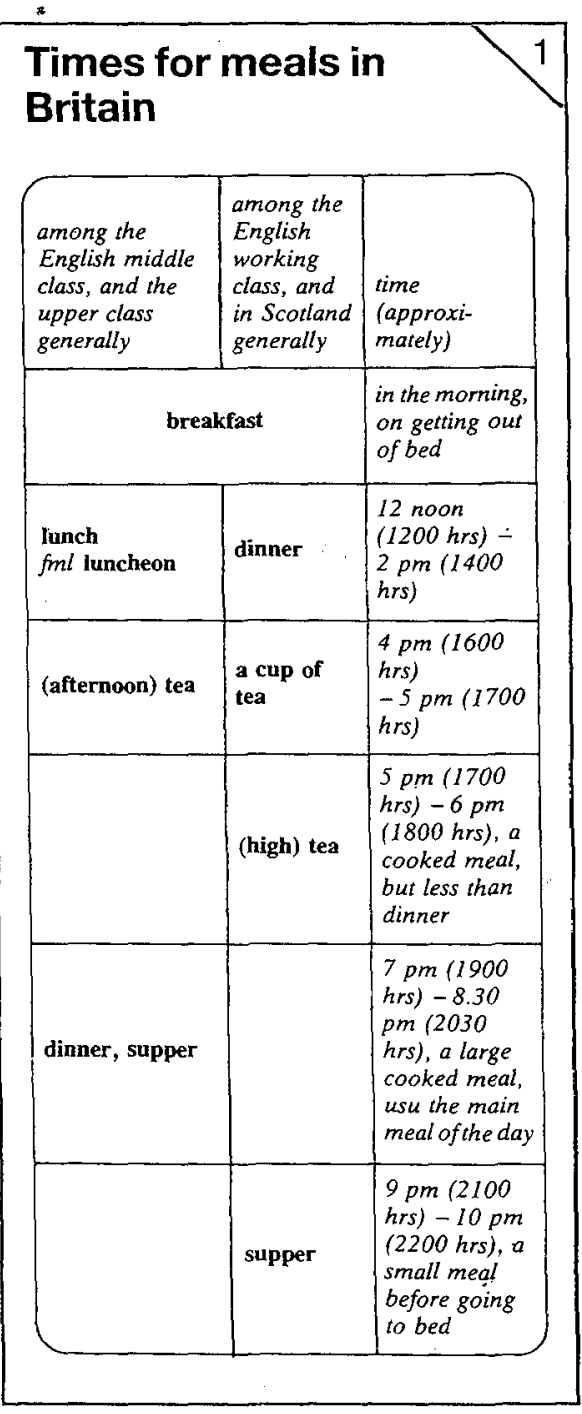

variability in the semantic field of meals has received a fairly acceptable description in dictionaries and similar works. But there are some divergent points that suggest that the description is incomplete and not entirely reliable. Thus, for example, for Collins and McArthur and for the OED, supper can be a large meal, whereas Newmark gives a simplified account when defining it only as a light meal; furthermore, for McArthur the term has social (middle-class) connotations when it refers to a main meal. No less simplified is the account that Newmark gives of luncheon whose usage is restricted only to nobility. With regard to tea, Collins underlines its use in northern England whereas McArthur finds it characteristic of Scotland. As for dinner as a midday meal, according to J. Clark's Harrap's Dictionary of English Usage (1990) the term is used by many, without further specification, while according to $M$. Manser's Bloomsbury Good Word Guide (1990) it is used by some, especially in Northern England and Scotland.

Certainly imprecisions and contradictions of this kind in dictionaries and linguistic studies are partly the result of brevity and condensation of presentation. Nevertheless, they are proof of the flaws and dangers implied in the description of language use when this is based only on the intuition of linguists, however skilled they might be.

\section{The survey}

In order to find firmer evidence I carried out a sample survey by interview, in which I asked informants to point out the different meals taken in an ordinary day, with their corresponding times and details about size (whether 'light' or 'substantial'). The interview was basically open, however; in the few cases in which the informants chose a term that fell outside the standard set considered here (for example, snack or evening meal), they were asked to give a further specification.

The research was carried out in two areas of England fairly distant from each other: Greater London, and Leeds and Sheffield, in Yorkshire, henceforth referred to as South and North. I obtained a random sample of 220 respondents for the South and 325 for the North, stratified according to sex (men and women), age (4 groups: under 25 , over 25 , 45 , and 60 ) and social class. For social class I grouped people into 4 categories on the basis of professional occupation $(\mathrm{P})$, by collapsing the classification of occupations used by Ivan Reid in Social Class Differences in Britain (1977), and also in accordance with the 4 broad socio-economic categories used by William Labov in The Social Stratification of English in New York City (1966):

\footnotetext{
P4: 'Professional': doctor, lawyer, university teacher ...

P3: 'Intermediate': manager, nurse, schoolteacher...
} 
P2: 'Skilled non manual': clerk, secretary, sales representative...

P1: 'Manual': bus conductor, carpenter, electrician ...

The data were analysed by means of a statistical program, the SPSS/PC +, and offered the overall results shown in Panel 2.

Comparing the two varieties, one notices that the use of the meal terms for midday, ordered from most to least frequent, follow the same pattern: lunch-dinner. Although in both regions lunch is the unmarked term, dinner is more frequently used in the North. As for the evening meal, the results offer a more striking difference: whereas in the South the order is dinner-tea-supper, and the occurrence of dinner is markedly higher, in the North the order is tea-dinner-supper. Furthermore, while in the South tea and supper have a similar distribution, in the North tea is more frequently used than dinner, and much more than supper.

The use of these terms in both regions is not uniform; it varies according to such social
Overall survey results

\begin{tabular}{l|r|r}
\hline & South & North \\
\hline Midday meal & & \\
Lunch & $91.8 \%$ & $69.8 \%$ \\
Dinner & $8.2 \%$ & $30.2 \%$ \\
Evening meal & & \\
Dinner & $70.7 \%$ & $44.6 \%$ \\
Tea & $17.2 \%$ & $52.3 \%$ \\
Supper & $12.1 \%$ & $3.1 \%$ \\
\hline
\end{tabular}

parameters as socioeconomic status (SES), education (ED), sex, and age. The SES and $\mathrm{ED}$ are in themselves interrelated in so far as they point to a single dimension or concept, social prestige, which turned out to be the most clear independent variable, as can be seen from the results in Panel 3.

Here, the use of lunch instead of dinner for midday, and of dinner vs. tea/supper, clearly correlates with professional status. The contrast between $\mathrm{P} 1 / \mathrm{P} 2$ and $\mathrm{P} 3 / \mathrm{P} 4$ is well marked

\section{Socioeconomic status}

\begin{tabular}{l|r|r|r|c|c|c|c|c}
\hline & \multicolumn{4}{|c|}{ South } & \multicolumn{4}{c}{ North } \\
\cline { 2 - 9 } & \multicolumn{3}{|c|}{ SES } & \multicolumn{4}{c}{ SES } \\
\cline { 2 - 9 } & P1 & P2 & P3 & P4 & P1 & P2 & P3 & P4 \\
\hline $\begin{array}{l}\text { Midday meal } \\
\text { Lunch } \\
\text { Dinner }\end{array}$ & $78.1 \%$ & $98.6 \%$ & $100.0 \%$ & $100.0 \%$ & $43.3 \%$ & $68.0 \%$ & $87.0 \%$ & $90.9 \%$ \\
Evening meal & $21.9 \%$ & $1.4 \%$ & & & $56.7 \%$ & $32: 0 \%$ & $13.0 \%$ & $9.1 \%$ \\
Dinner & & & & & & & & \\
Tea & $61.1 \%$ & $74.2 \%$ & $76.7 \%$ & $84.0 \%$ & $25.8 \%$ & $44.3 \%$ & $49.2 \%$ & $64.2 \%$ \\
Supper & $34.7 \%$ & $12.9 \%$ & $4.7 \%$ & & $72.7 \%$ & $52.6 \%$ & $46.3 \%$ & $32.8 \%$ \\
\hline
\end{tabular}

Education

\begin{tabular}{l|r|r|r|r|r|r}
\hline & \multicolumn{3}{|c|}{ South } & \multicolumn{3}{c}{ North } \\
\cline { 2 - 7 } & \multicolumn{1}{c|}{ ED1 } & ED2 & ED3 & ED1 & ED2 & ED3 \\
\hline Midday meal & & & & & & \\
Lunch & $81.7 \%$ & $98.5 \%$ & $100.0 \%$ & $46.7 \%$ & $73.9 \%$ & $86.2 \%$ \\
Dinner & $18.3 \%$ & $1.5 \%$ & & $53.3 \%$ & $26.1 \%$ & $13.8 \%$ \\
Evening meal & & & & & & \\
Dinner & $63.7 \%$ & $75.1 \%$ & $76.3 \%$ & $27.1 \%$ & $50.5 \%$ & $54.9 \%$ \\
Tea & $34.1 \%$ & $6.4 \%$ & $3.4 \%$ & $71.0 \%$ & $45.1 \%$ & $41.8 \%$ \\
Supper & $2.2 \%$ & $18.5 \%$ & $20.3 \%$ & $1.9 \%$ & $4.4 \%$ & $3.3 \%$ \\
\hline
\end{tabular}


Sex

\begin{tabular}{l|r|r|r|r}
\hline \multirow{2}{*}{} & \multicolumn{2}{|c|}{ South } & \multicolumn{2}{c}{ North } \\
\cline { 2 - 5 } & Male & Female & Male & Female \\
\cline { 2 - 5 } Midday meal & & & & \\
Lunch & $87.3 \%$ & $97.0 \%$ & $65.0 \%$ & $74.4 \%$ \\
Dinner & $12.7 \%$ & $3.0 \%$ & $35.0 \%$ & $25.6 \%$ \\
$\begin{array}{l}\text { Evening meal } \\
\text { Dinner }\end{array}$ & $69.0 \%$ & $72.8 \%$ & $40.9 \%$ & $47.8 \%$ \\
Tea & $19.8 \%$ & $14.1 \%$ & $56.0 \%$ & $49.1 \%$ \\
Supper & $11.2 \%$ & $13.1 \%$ & $3.1 \%$ & $3.1 \%$ \\
\hline
\end{tabular}

in the North. The use of dinner for the midday is only evident among the working classes (P1), especially in the North where its occurrence is higher than lunch. As for tea, its use is higher for dinner in the two lower groups (P1, P2) and it is only clearly rejected among the highest $\mathrm{P} 4$.

As for the second indicator, education, the use of the pair lunch-dinner is higher among the more educated. This is especially true in the case of lunch, which reaches a categorical use $(100 \%)$ among the ED3 group in both areas. Conversely, the variants dinner-tea diminish with education and in the North they are the most frequently used among the less educated (ED1).

It should be pointed out that the data refer to the most natural context since some variation was observed, especially in the North. There people, particularly in the higher social classes and among the more educated, who answered lunch-dinner first, when asked a second time to relate their use directly to the most familiar situations, as when with family or friends, shifted to lunch (or dinner) and tea. This was a clear indication that, despite the greater frequency of use of tea (and of dinner among Pl speakers), it is the pair lunchdinner that is felt as the mark of prestige.

As to the sex variable, an analysis of the data in Panel 4 shows that the prestigious pair lunch-dinner is more frequently used among women in the two regions, which is in agreement with Labov's proposition that women are more sensitive than men in such matters.

Finally, the age differences also have an effect on the use of the terms, although the correlation of this variable is not so clear, at least it is not so clearly perceived by speakers. However, an examination of the data leads us to notice an interesting contrast between the two surveys: see Panel 5. Whereas in the South the frequency of the prestigious variants lunch and dinner is higher among the younger group (-25), in the North it is lower. In the South the higher frequency of these terms within this group should be considered as revealing the stage reached by the process of change. Conversely, in the North its lower frequency could be understood in the light of various factors: in a situation of great variability in the use of the terms the younger group is prone to be less sensitive to the mark of prestige for, since they are still under parental influence, they are more inclined to use the variant (especially tea) which is more frequently employed in their family environment, the more so if it is associated with a system of values. In addition to this, one could consider at this age the influence of the phrase school dinner, especially among high

\begin{tabular}{l|r|r|r|r|r|r|r|r}
\hline & \multicolumn{4}{|c|}{ South } & \multicolumn{4}{c}{ North } \\
\cline { 2 - 8 } & \multicolumn{3}{|c|}{ Age } & \multicolumn{3}{c}{ Age } \\
\cline { 2 - 8 } & 1 & 2 & 3 & 4 & 1 & 2 & 3 & 4 \\
\hline Midday meal & & & & & & & & \\
Dunch & $97.7 \%$ & $92.0 \%$ & $91.9 \%$ & $86.0 \%$ & $52.2 \%$ & $72.9 \%$ & $84.1 \%$ & $70.9 \%$ \\
Dinner & $2.3 \%$ & $8.0 \%$ & $8.1 \%$ & $14.0 \%$ & $47.8 \%$ & $27.1 \%$ & $15.9 \%$ & $29.1 \%$ \\
Dinner & & & & & & & & \\
Tea & $72.1 \%$ & $65.5 \%$ & $81.1 \%$ & $70.8 \%$ & $33.3 \%$ & $42.1 \%$ & $53.1 \%$ & $52.7 \%$ \\
Supper & $11.6 \%$ & $20.7 \%$ & $16.2 \%$ & $16.7 \%$ & $64.4 \%$ & $54.7 \%$ & $40.7 \%$ & $47.3 \%$ \\
\hline
\end{tabular}


school adolescents who were also included in the sample.

Informants were invited to make comments, and asked whether there were any differences in the naming of the meals over the weekend and with reference to those taken away from home in a restaurant.

In general, it emerged that, on the weekend, especially on Sunday, there is a delay in the two first meals, to such an extent that breakfast is often turned into brunch or late breakfast (about 11) and lunch into dinner, which becomes a more elaborate family meal. A Sunday lunch, however, is also common, especially in restaurants. When that is so, the evening meal becomes tea and its time stays the same (about 6 p.m.). All the respondents agreed in pointing at dinner as the most appropriate term in a restaurant in the evening.

\section{A brief look at other languages}

On the basis of the data gathered on the names of meals in English, French and Spanish in a previous study, I have drawn the diagram in Panel 6 to show their similarities and differences and to gain new insights into the nature of factors at work in their presentday usage and in the changes undergone.

Meals on the whole follow the tripartite schema of ancient times. As the arrows indicate, the most outstanding feature has been the gradual displacement of meals with the increasing modernization of society, which is well reflected in the variation of meaning of some terms. The most extreme case is French diner and English dinner, which, like Portuguese jantar, have switched from a morning to an evening meal.

Semantic changes in the names of meals have not been sudden or completely uniform, which has resulted in various ambivalences: $\mathrm{Sp}$. almuerzo and Fr. dejeuner are used as breakfast as well as midday meal, and Fr. diner and $\mathrm{E}$. dinner refer to both midday and evening meals. The new forms introduced as a result of this displacement were first adopted by the highest strata of society. In Fr. diner and $\mathrm{E}$. dinner, the change from breakfast to midday originated at the medieval court, as happened some time later with the Spanish change from yantar to comida. More recently, we could point to the replacement of dinner by lunch, and supper (and tea) by dinner due to the influence of the emerging middle class, and the same social meaning can be attributed to the change from cena to comida in some countries of Latin America.

In effect, following the path of the Roman tradition, the evening meal today constitutes the meal par excellence, and this is true in Europe as well as America, Spain being a really atypical case. In this light we can understand the differences between $\mathrm{Sp}$. cena and AmSp. comida, which is nearer to the North American or Anglo-Saxon tradition.

The general tendency, especially in the urban middle class, is to disfavour terms like tea or supper in English, souper in French, and to a lesser extent cena in American Spanish, unless they are used to designate minor meals (intermediate afternoon tea or late supper, Fr. souper, $\mathrm{Sp}$. cena), thus giving them a specialized meaning.

These languages show a remarkable parallelism in the geographical distribution of some of their meal variants. If in Britain, the emerging pattern, lunch-dinner, takes place predominantly in the South, and the old system, dinner-tea (and to a lesser degree supper) in the North, the pattern to be generalized in the North of France is déjeuner-diner whereas in many areas of the South dinersouper is most common. In both cases the 'modern' system is particularly linked to the metropolitan areas of their respective countries: London and Paris.

ETT

Similarities and differences in French, English and Spanish

\begin{tabular}{|c|c|c|c|}
\hline French & Br.English & Am. English & Spanish \\
\hline 1. (petit) dejeuner & $\begin{array}{l}\text { breakfast } \\
\text { lunch/dinner } \\
\swarrow \\
\text { dinner/supper/tea }\end{array}$ & $\begin{array}{l}\text { breakfast } \\
\text { lunch/dinner } \\
\text { dinner/supper }\end{array}$ & $\begin{array}{c}\text { desayuno/(almuerzo) } \\
\swarrow \\
\text { comida/almuerzo (*yantar) } \\
\searrow \\
\text { cena/comida }\end{array}$ \\
\hline
\end{tabular}

